Letter to the Editor

\title{
Curvilinear branching retinal deposits in acute syphilitic posterior placoid chorioretinitis: a novel pattern on en-face optical coherence tomography
}

Tom Ayton MD, ${ }^{1}$ Roderick O'Day $\mathrm{MBBS}^{2}$ Dean R Cugley $\mathrm{MBBS}^{2}$ and Xavier Fagan FRANZCO ${ }^{2}$

${ }^{1}$ Liverpool Hospital, corner of Goulburn and Elizabeth Streets, Liverpool, NSW 2170, Australia

${ }^{2}$ Medical Retina Unit, Royal Victorian Eye and Ear Hospital, 32 Gisborne Street, East Melbourne, Vic 3002, Australia

Correspondence: Dr Xavier Fagan, Royal Victorian Eye and Ear Hospital, 32 Gisborne Street, East Melbourne, Vic 3002, Australia

Email: xavier.fagan@eyeandear.org.au

Received 15 February 2019; accepted 28 April 2019

Funding sources / Financial disclosure: None

Conflict of interest: None

This is the author manuscript accepted for publication and has undergone full peer review but has not been through the copyediting, typesetting, pagination and proofreading process, which may lead to differences between this version and the Version of Record. Please cite this article as doi: $10.1111 /$ ceo.13557

This article is protected by copyright. All rights reserved. 
Acute syphilitic posterior placoid chorioretinitis (ASPPC) is an intraocular infection caused by the spirochete Treponema pallidum. The typical appearance of ASPPC on colour photography is of the presence of a large, round, yellow placoid lesion in the posterior pole. Optical coherence tomography (OCT) images reflect various outer retinal changes including photoreceptor and ellipsoid zone disruption, nodular and hyper-reflective thickening of the retinal pigment epithelium (RPE) and sub-retinal fluid. ${ }^{1}$ We present the case of a novel, curvilinear branching pattern on the surface of the retinal pigment epithelium (RPE) on en-face OCT of an ASPPC lesion.

The patient presented to our clinic with a two-day history of painful, reduced vision in both eyes, best-corrected visual acuity (BCVA) in the right eye was 6/18 and left eye 6/9. Intraocular pressures were within normal limits (right eye $16 \mathrm{mmHg}$, left eye $13 \mathrm{mmHg}$ ). Slit lamp examination revealed bilateral panuveitis with $1+$ cells in the anterior chamber of both eyes and large keratic precipitates in the left eye. In the anterior vitreous there were $2+$ cells in the right eye and 1+ cells in the left eye. Fundoscopy revealed a pale placoid lesion in the right macula and nasal to the optic disc. (Fig. 1) The left retina had an unremarkable appearance.

Spectral domain OCT imaging was performed with Spectralis SD (Heidelberg Engineering, Heidelberg, Germany). OCT of the right eye revealed loss of the ellipsoid layer and hyper-reflective lesions on the surface of the RPE (Fig. 2). These areas of hyper-reflectance on the OCT correlated with a curvilinear branching pattern in the outer retina that spared the fovea on en-face imaging of the outer retinal slab of the transverse structural OCT analysis. (Fig. 3)

Systemic investigations were consistent with active syphilitic infection with a positive rapid plasma reagin, a reactive treponema pallidum particle agglutination assay and treponema pallidum IgM antibody. Inflammatory markers and liver function tests were elevated. HIV serology, chlamydia and gonorrhoea urine PCR were negative. A 
new diagnosis of hepatitis $\mathrm{C}$ was made after further workup. The patient was treated with intravenous benzylpenicillin for 15 days, a short course of oral prednisone and referred to the gastroenterology team for hepatitis $C$ treatment. Following two weeks of therapy the patient's vision improved, BCVA in the right eye 6/9.6 and left eye 6/7.5. Unfortunately, the patient was then lost to follow-up.

The pathogenesis of the retinal deposits in ASPPC is unclear and not well understood. To our knowledge, the curvilinear branching pattern on the en-face OCT analysis has not been described in the literature previously. It is different to previous reports of en-face OCT imaging that showed multifocal dots at the level of the RPE. ${ }^{1}$ The branching pattern may represent immune complex deposits on the surface of the $\mathrm{RPE}^{2}$ or shed photoreceptor outer segments. ${ }^{3}$ Fundus autofluorescence may have been helpful in distinguishing the nature of the material but was not performed. A purely speculative explanation of the pattern seen in this case may be related to the hexagonal arrangement lobules in the choriocapillaris, which is supplied by a single arteriole from Sattler's layer. ${ }^{4}$ The deposits may accumulate in the outer edges of these hexagons because of reduced capacity for absorption into the choriocapillaris.

As the use of multimodal imaging in ASPPC and other retinal disease increases, it remains to be seen whether this interesting pattern may yet become a specific diagnostic sign or whether it will help further advance the pathogenesis of ASPPC. 


\section{REFERENCES}

1. Zett C, Lima LH, Vianello S et al. En-face optical coherence tomography of acute syphilitic posterior placoid chorioretininopathy. Ocul Immunol Inflamm. 2018; 26(8): 1264-1270.

2. Lima LH, de Andrade GC, Vianello S et al. Multimodal imaging analysis of hyppereflective dot-like lesions in acute syphilitic posterior placoid chorioretinopathy. Ocul Immunol Inflamm. 2017; 7(1) doi: 10.1186/s12348 016-0119-7.

3. Pichi F, Ciardella MD, Cunningham ET et al. Spectral domain optical coherence tomography findings in patients with acute syphilitic posterior placoid chorioretinopathy. Ret-J Ret Vit Dis. 2014; 34(2): 373-383.

4. Nickle DL, Wallman J. The multifunctional choroid. Prog Retin Eye Res. 2011; 29(2): 144-168.

\section{FIGURE LEGENDS}

Figure 1: Colour photograph of the right eye revealing two pale placoid retinal lesions: in the macula and nasal to the optic disc.

Figure 2: OCT of the right eye displaying multiple hyper-reflective lesions on the surface of the retinal pigment epithelium and a loss of the ellipsoid zone.

Figure 3: En-face transverse structural OCT of the right eye displaying a curvilinear branching appearance (above) correlating with hyper-reflective lesions on the transverse OCT image (below). 

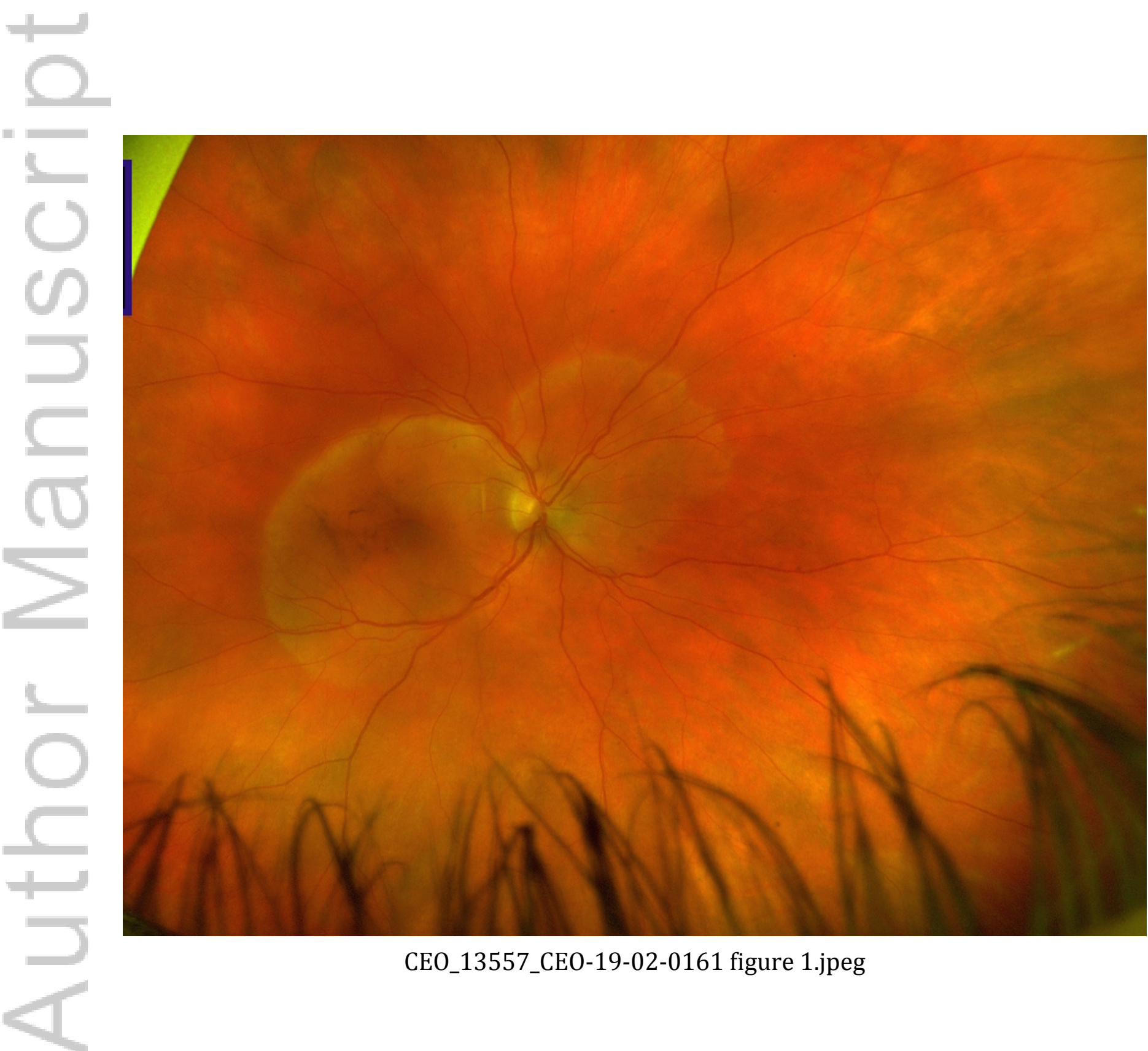

CEO_13557_CEO-19-02-0161 figure 1.jpeg

This article is protected by copyright. All rights reserved. 


\section{University Library}

\section{- M M I N E R VA \\ A gateway to Melbourne's research publications}

Minerva Access is the Institutional Repository of The University of Melbourne

Author/s:

Ayton, T;O'Day, R;Cugley, DR;Fagan, XJ

Title:

Curvilinear branching retinal deposits in acute syphilitic posterior placoid chorioretinitis: A novel pattern on en face optical coherence tomography

Date:

2019-09-01

Citation:

Ayton, T., O'Day, R., Cugley, D. R. \& Fagan, X. J. (2019). Curvilinear branching retinal deposits in acute syphilitic posterior placoid chorioretinitis: A novel pattern on en face optical coherence tomography. CLINICAL AND EXPERIMENTAL OPHTHALMOLOGY, 47 (7), pp.952-954. https://doi.org/10.1111/ceo.13557.

Persistent Link:

http://hdl.handle.net/11343/286115 